\title{
EMOTIONAL INTELLIGENCE AND LEADERSHIP - THE DARK AND BRIGHT SIDES
}

\begin{abstract}
Emotional intelligence (EQ), as any set of abilities or skills has two sides, bright and dark ones. A person can employ their social abilities and high emotional skills for prosocial behavior or could use it in maladaptive ways to manipulate others to achieve self-centered outcomes. The current paper explores the relationship between emotional intelligence (EQ) and leadership through a literature synthesis. It discusses the dark side of emotional intelligence, the negative aspects of emotional intelligence. It also provides an overview of emotional intelligence and leadership concepts, and discusses the three primary constructs of emotional intelligence, their augmentation to the theory. Finally, it closes with hypothetical synopses of the leader's usage of emotional intelligence.
\end{abstract}

Keywords: Emotional intelligence, leadership, dark side, prosocial behavior.

\section{INTRODUCTION}

For ages life has been saturated with requests that required not only mental and physical abilities but also social and emotional capabilities. Emotional intelligence is one of the recent theories that have appeared in the field of management and as one of the most modern types of intelligence in the field of psychology.

After the publication of the best seller book Emotional Intelligence by Daniel Goleman (1995), the concept has become an influential theory that captivated the attention of various scientific fields, including management (Bar-On, 2006). According to Golman (1995), the cognitive intelligence quotient (IQ) contributes only by 20 percent of the factors that influence and direct success in life, while the other 80 percent relates to additional factors that the individual has, including the emotional intelligence (Goleman, 1995).

The concept of leadership is one of the most well-known principles of human sciences with an administrative nature. Leadership is a social role presented by the leader throughout its interaction with other members of the group (Kerr et al., 2006). Where the leader provides the guidance and direction for the individuals to achieve the group's goal and the leader is responsible for understanding the emotions of individuals and what has a touch on their behavior, and do what he can to monitor these emotions and regulate them (Kerr et al., 2006). Here the good role of emotional intelligence emerges between

\footnotetext{
1 Tareq Lubbadeh, Ph.D. candidate, at the University of Pécs, Faculty of Business and Economics, University of Pécs, Pécs, Rákóczi út 80, 7622, Hungary; e- mail: Tareq.Lubbadeh@yahoo.com; ORCID: 0000-0002-8118-8775.
} 
the quintessential skills that provide the leader with the ability to manage these emotions positively.

On the other hand, some experts and researchers are debating about the shady side of emotional intelligence. A person can employ their social abilities and their high emotional intelligence to dominate the perceptions of others, manipulate them, guide them to the wicked path, or use those skills to advance at the cost of others (Kilduff, Chiaburu and Menges, 2010; Côté et al., 2011; Nozaki and Koyasu, 2013; Austin et al., 2014; Chamorro-Premuzic and Yearsley, 2017).

Accordingly, this research aims to canvass the relationship between emotional intelligence and leadership, to obtain a more profound understanding of both terms, to investigate the leader's usage of EQ and to what extent the EQ plays a role in the success of leaders. In addition, the paper looks into the dark side of the EQ the negative aspects of emotional intelligence. Thus, the present article offers an overview of the idea of emotional intelligence and leadership by reviewing the most relevant previous literature.

The paper is formed as follows. Within the first section, we endeavor to wage an overview of the emotional intelligence concept, definition, and the most influential models. Follow this the relationship between the two concepts. Furthermore, we explore the dark side of emotional intelligence - finally, Conclusion, contribution, and possible future research studies.

\section{WHAT IS EMOTIONAL INTELLIGENCE?}

The concept of emotional intelligence is one of the significant theory that captivated the attention of scientists and scholars (Mayer, Dipaolo and Salovey, 1990; Goleman, 1995; Mayer and Salovey, 1997; Goleman, 1998; George, 2000; Petrides and Furnham, 2001; Bar-On, 2004, 2006; Singh, 2006). Scientists and researchers have presented multiple definitions and various models of emotional intelligence since its inception. The areas of agreement between these definitions and models are more than the differences; however, a number of those definitions have been emphasized on a set of abilities, while other explanations have been stressed on a set of personality traits, social, and emotional skills.

In 1920, Edward Thorndik laid the earliest seeds of this theory when he suggested that humans possess different sorts of intelligence, one of them called "social intelligence", and defined it as the ability to understand and interpret one's own and others' emotions and behavior so that they can function effectively in human relations (Salovey and Mayer, 1990; Singh, 2006). Later, Howard Gardner (1983), dropped the traditional concepts of intelligence, in his book Multiple Intelligences when he developed the theory of multiple intelligence to comprises two types of personal intelligence; the interpersonal (social), and intrapersonal (emotional) intelligence, which is equally essential to the typical type of intelligent (Cherniss, 2001; Bar-On, 2006). Then, Salovey and Mayer (1990), who initially coined the term of "Emotional Intelligence" to express emotional characteristics; this was the first use of this concept, which later began to spread among interested scholars (Salovey and Mayer, 1990). Salovey and Meyer define emotional intelligence as: "subset of social intelligence that involves the ability to monitor one's own and others' feelings and emotions, to discriminate among them and to use this information to guide one's thinking and actions" (Salovey and Mayer, 1990). 
Mayer and Salovey assume that every task in life is abundant with emotional information, and this information must be processed to guide our thought and behavior. Later Meyer and Salovey (1997) revised their definition of emotional intelligence and divided into four abilities: Perceiving Emotion, Integrating Emotion, Understanding Emotions, and Managing Emotions (Mayer and Salovey, 1997).

According to Goleman (1995), emotional intelligence is a collection of skills and abilities that enable an individual to understand his or her feelings and those of others, which are necessary for our interaction with others and to success in professional communications (Goleman, 1995). While Bar-On (1997), defines Emotional-Social Intelligence as: "a cross-section of interrelated emotional and social competencies, skills and facilitators that determine how effectively we understand and express ourselves, understand others and relate with them, and cope with daily demands" (Bar-On, 2006). Bar-On refers to emotional intelligence as Emotional Social Intelligence (ESI), as his definition combines both psychological and social competencies. George (2000) defined emotional intelligence as: "the ability to perceive feelings through thinking, understanding emotional knowledge and organizing emotions so that the individual can influence the feelings of others" (George, 2000).

Many definitions have addressed emotional intelligence in the recent period; these definitions agreed on one or more of the following:

1. The ability to understand, harmonize, and display one's feelings and emotions.

2. The ability to recognize, interpret, and communicate with other people's feelings and emotions.

3. Employing these capabilities can help the individual to manage and control impulses and stress, resolving interpersonal and intrapersonal complexities, and make the appropriate decisions.

Thus, an emotionally intelligent person is more able to cope with the variations that affect their surroundings more equipped to succeed in personal relationships and to build a social support network, compared to other (Mayer et al., 2001).

\section{EMOTIONAL INTELLIGENCE MODELS}

Researchers and scholars have produced four primary models of emotional intelligence, each with its novel forms and instruments for measuring EQ. The models are: the ability EQ model (Salovey and Mayer, 1990) which uses a self-assessment tool called the MSCEIT. Two mixed; models the Goleman model or the "competency model" (Goleman, 1995) that uses the 360-degree assessment Emotional and Social Competency Inventory (ESCI), and the Bar-on model (Bar-On, 1997, 2000) which uses the Emotional Quotient Inventory (EQi). The fourth model is the trait model or the "trait emotional self efficacy" (Petrides and Furnham, 2001).

The main variation between the three models is whether the model focuses on a set of mental abilities or a set of personality traits. The ability model focuses on emotions themselves, while the EQ mixed model focuses on both emotions and personality traits as one (Mayer, Caruso and Salovey, 2000). In contacts, the trait model focuses on self-perceptions personality traits (Petrides, 2010). 


\subsection{The ability model}

The ability model of emotional intelligence indicates that emotions provide the person with relevant information; the person will process the information, then benefit from it, and finally respond to them to cope with the problem or the tense situation more intelligently. Being aware of emotions makes our thinking smarter (Mayer et al., 2001; Mayer, Salovey and Caruso, 2004).

Mayer and Salovey conceptualized a four branch model to apprehend emotional intelligence as a cognitive ability; it presents four levels through which a person becomes emotionally intelligent (Mayer and Salovey, 1997).

The ability four-branch model comprised perceiving emotions: the person's ability to utilize his or her emotions or the emotions of others and combine these emotions into the thinking process to facilitate the performance of various tasks. Using emotions: refers to a person ability to utilize his or her emotions or the emotions of others and combine these emotions into the thinking process to facilitate the task. Understanding emotions: which is the ability to understand emotional language and identify complicated relationships among emotions, and the readiness to classify emotions, to determine their causes and outcomes. Managing emotions: the ability to compose compelling strategies for managing one's own and others' emotions to help in achieving the desired result, rather than being affected by it in unpredictable ways (Mayer, Salovey and Caruso, 2004; Mayer, Caruso and Salovey, 2016). In 2016, Mayer, Caruso, and Salovey updated the ability model; by introducing more significant areas of problem-solving to the ability model (Mayer, Caruso and Salovey, 2016)

Mayer et al. (1990), distinguished between the ability model and other models (mixed model), that these alternatives models combine a wide variety of non-ability and traits variables, as opposed to the ability, model, which focuses on actual abilities, perceiving, using, understanding, and managing emotions (Mayer, Caruso and Salovey, 1999).

\subsection{Goldman's Competency Model}

Daniel Goleman, a psychologist, and journalist, known best for his work on emotional intelligence. Goleman was the first to use the notion of emotional intelligence to business through his article (1998) in Harvard business review, "What makes a leader?" (Gayathri and Meenakshi, 2013).

Goleman's (1998) model of emotional intelligence outlines four branches. Each branch composes a variety of extensive competencies and skills that boost performance: the first two dimensions, self-awareness, and self-management described as personal Competence. Social awareness and relationship management described as social competencies. According to Goleman, these competencies are learned abilities that emerged from the fundamentals (Goleman, 1998).

The four-branch model comprised self-awareness, which is the ability to know what we are feeling, why we think this way, and how we react to those feelings. Selfmanagement reflects the ability to manage our distressing emotions and impulses in practical ways. Social awareness refers to the ability to know, understand, and respond to other people's feelings. Relationship management, which means the ability to combine the first three branches to influence, inspire, and to manage conflict (Goleman, 1998, 2002).

The Goleman model differs from Salovey and Mayer's model of emotional intelligence is that he added several personality characteristics like Leadership, Collaboration, and Conscientiousness (Gayathri and Meenakshi, 2013). 


\subsection{Bar-On's Emotional Social Intelligence model}

Bar-On introduced the first self-report measure of EQ the Emotional Quotient Inventory' (EQ-i), which attempts to estimate emotional intelligence (Bar-On, 2006; Singh, 2006). Bar-On refers to EQ as the "Emotional Social Intelligence" (ESI), where it combines emotional and social competencies. The model outlines five key elements: intrapersonal, interpersonal, adaptability, stress management, and general mood; each one of these elements contains several skills and competencies. These skills and competencies focus on the potential for success (Bar-On, 2004).

Bar-On recognizes emotional intelligence as five non-cognitive competencies: Interpersonal (covering Empathy, Social Responsibility, and Interpersonal Relationship); Stress Management (covering Stress Tolerance and Impulse Control); Adaptability (covering Reality-Testing, Flexibility, and Problem-Solving); and General Mood (covering Optimism and Happiness) (Bar-On, 2006).

The distinction between the two models (Bar-On and Goleman), is that the Bar-On model includes stress management and general mood elements (Gayathri and Meenakshi, 2013).

\subsection{The Trait model}

The trait EI model or "trait emotional self - efficacy", was developed by Petrides and Furnham $(2000,2001)$, as a type of measurement that defines the constitution of the model (Petrides and Furnham, 2000, 2001). According to Petrides and Furnham (2003), the Trait EI model" refers to a constellation of emotion-related self-perceptions and dispositions, assessed through self-report "(Petrides and Furnham, 2003).

Petrides and Furnham proposed a conceptual contrast between the ability model and the trait model of emotional intelligence. The critical foundation for this distinction between the two models is that the trait model involves emotion related to self-perceptions personality traits like "optimism", measured through established self-report measures. In contacts, the ability model focuses on emotion-related to mental ability like "Using emotions" (cognitive ability), measured through maximum performance tests that have shown to be resistant to scientific standards (Petrides and Furnham, 2000, 2001, 2003).

Petrides views the Trait model as a construct composed of four significant scales: Emotionality, represent the self-efficacy in perception and interpretation of emotions. Sociability, represent the self-efficacy in interpersonal interactions, management, and regulation of others' emotions. Well-being, outline traits linked to personality dispositions. Self-control, consisting of self-efficacy in feeling, and impulse regulation (Kaliská and Kaliský, 2016; Petrides and Mavroveli, 2018).

Based on what has displayed above, we can state that emotional intelligence consists of a set of emotional and social skills. That provides the individual with the ability to understand self and others' emotions, which provide him with the aptitude to involve and interact with others and enable him to succeed on the personal, professional, and social level.

One of the most influential criticisms faces the theory of emotional intelligence is the multiplicity of methods and approaches that explain the EQ; there is not only one model that the researchers rely upon when studying this phenomenon, besides, the lack of agreement among researchers on the definition of emotional intelligence (Emmerling and Goleman, 2003). 


\section{EMOTIONAL INTELLIGENCE AND LEADERSHIP}

Leadership is one of the most used concepts in which emotional intelligence has been correlated with (Higgs and Aitken, 2003; Kerr et al., 2006). In the domain of EQ and leadership, Daniel Goleman, consider as a pioneer in this field. He questioned the supremacy of intelligence quotient (IQ), through expanding the awareness of EQ importance as a component in leadership and organization success (Goleman, Boyatzis and McKee, 2002).

Golman (1995) suggested that EQ plays an indispensable role in the success of a person in the work environment, job performance, and leadership (Goleman, 1995). Goleman et al. (2002) used the idiom "primal leadership", which indicates leading by emotion, the best leader is who can assist other people in reaching and staying in the most desirable emotional mood (Goleman, Boyatzis and McKee, 2002). According to Goleman et al. (2002), several studies have shown that the leader's feelings and emotions are contagious to the other in the group. If the leader is in an "upbeat" mood, people will catch that mood, become more confident about their ability and skill to perform, creativity improves, and decision-making improves. In contracts, if the leader in a "downbeat" mood, people will catch that mood, and performance goes down (Goleman, Boyatzis and McKee, 2002).

George (2000) suggested that EQ plays an essential role in leadership effectiveness. George explains that EQ heightens the leader's ability to solve, organize, and approach issues and opportunities that challenge them, their followers, and their organization. Specifically, George suggests that leaders high on emotional intelligence are more effective in influencing and understanding their followers' emotions, thereby gaining their support and responsiveness toward the organization's goals and objectives (George, 2000). Caruso et al. (2001) have also discussed the relationship between EQ and leadership effectiveness. The authors used the four branch model (the ability model), developed by Mayer and Salovey (1997), to ground the EQ role in expediting the work of an effective leader. For example, understanding emotions provide the leader with the ability to recognize the relationship between complicated feelings. Also, this ability offers the leader information on why people behave like this. Managing emotions, allows the leader to control his emotions and feelings, such as stress, fear, and joy (Caruso, Mayer and Salovey, 2001).

Gardner and Stough (2002), in their study, investigated the relationship between EQ and the leadership style (transformational, transactional, and laissez-faire). They surveyed 110 high- level managers. The study found a clear connection between transformational leadership and overall emotional intelligence, while no correlation found between emotional intelligence and transactional and a negative relationship between laissez-faire leadership and emotional intelligence has been obtained (Gardner and Stough, 2002).

Wong and Law (2002), in their article, developed a compact EQ measure that can be applied in management and leadership researches. Besides, they investigated the effects of EQ of the leader and follower on performance and satisfaction. The study found that the emotional intelligence of the leaders influences reimbursement and extra-role behavior of the followers. Nevertheless, the study reported no connection between the EQ of the leaders and the subordinate job performance, while the emotional intelligence of followers affects both job performance and satisfaction (Wong and Law, 2002). 
In a different study, Rego et al. (2007) investigated the correlation between leader EQ and employee creativity. The study sample consisted of 138 top and middle managers, from 66 various businesses running in the EU. The exploratory study reached remarkable results, the most prominent of which is that the leader EQ explain significant variance in creativity dimensions. The research revealed that emotionally intelligent leaders operate in ways that inspire creativity among their followers (Rego et al., 2007). Likewise, Castro et al. (2012) conducted a study to investigate the connection between emotional intelligence and employee's creativity. The study sample consisted of 7 leaders and 66 followers from the most significant healthcare organization operating in the Iberian Peninsula. The study reached several results; the most important of the results were; finding a positive relationship between the EQ of managers and the creativity of the employees. Also, they found a connection between creativity and emotional intelligence outlined in the self-encouragement and understanding of their own emotions (Castro, Gomes and de Sousa, 2012).

Furthermore, Bratton et al. (2011), examines the influence of elements of EQ, on the self-other agreement and leadership performance. The study sample consists of 146 managers and 1,314 subordinates working in a large international technology company in North America. The study reached some results, the most distinguish result of which is that the relationship between EQ and leader performance is most reliable for managers who underestimate their leadership abilities. Moreover, it seems to be a negative correlation between EQ and leader performance for managers who exaggerate their leader capabilities (Bratton et al., 2011). Finally, Rosete and Ciarrochi (2005) examined the relationship between emotional intelligence and leadership effectiveness, among a sample of 41 senior managers. The study used the Ability-based measure (MSCEIT) to evaluate $\mathrm{EQ}$, and an objective measure of performance and a 360 assessment to assess leadership effectiveness. The study reported that higher EQ scores were correlated with more leadership effectiveness (Rosete and Ciarrochi, 2005). Olakitan (2014) also examined the influence of emotional intelligence on the leader's perceived effectiveness. The study administered on a purposeful sample of 232 respondents from an organization in Lagos city. The most significant findings of the research were that leadership is a critical factor in the success or failure of an organization. The study reported a positive relationship between EQ and perceived leadership effectiveness and outcomes. Furthermore, the study implies that leaders who use EQ to establish well-built relationships also do well in their jobs (Olakitan, 2014).

All in all, these studies demonstrate luculent evidence of the advantages of higher EQ to leadership efficiency. Developing EQ skills among leaders could have a significant influence on performance, decision-making, employee support, and relationships within the organization.

\section{THE DARK SIDE OF EMOTIONAL INTELLIGENCE}

In contrast, to the scrutinize view of $\mathrm{EQ}$ as definite clout in work, health, and relationships. (Goleman, 1995, 1998; George, 2000; Caruso, Mayer and Salovey, 2001; Cherniss, 2001; Gardner and Stough, 2002; Goleman, Boyatzis and McKee, 2002). Researchers have neglected the possibility that EQ can have a dark side. Simultaneously, a growing number of researchers are debating about the potential that people who have high EQ can employ their abilities in more malignant and dishonest ways, to meet their 
interests, even at the expense of others (Côté et al., 2011; Austin et al., 2014). For example, Kilduff et al. (2010) suggested that people with high EQ - in case of limited resources in an organization - are likely to use their high EQ to promote their best interests or even to manipulate others for strategic outcomes. Kilduff et al. (2010) hypothesized four dark-side approaches based on (Salovey and Mayer) four branches' ability model, which can be used by high EQ people. For example, disguising and expressing emotions for personal gain, here, a leader can frame his self-interests action or goal as indifferent action (Kilduff, Chiaburu and Menges, 2010). Likewise, Nozaki and Koyasu (2013), in their empirical study, investigated how trait EQ linked to interacting with ostracized others who try reprisal. They found that people with high interpersonal EQ try to manage others' emotions based on their own goals (Nozaki and Koyasu, 2013). By the same token, Nagler et al. (2014) investigated the relationship between socio-emotional intelligence (SEI) - consist of social intelligence, emotional intelligence, and various ability and traits- and the Dark Triad (narcissism, Machiavellianism, and psychopathy) that would predict emotional manipulation. The study found that the dark triad narcissism could expedite the use of EQ skills to manipulate other people's emotions. However, a mixed association with psychopathy and negative with Machiavellianism and EQ. Also, the study posits that EQ skills and ability can be used for wicked intentions (Nagler et al., 2014). Adam Grant (2014), in his essay for The Atlantic, "The Dark Side of Emotional Intelligence" explained that the person who could understand people's emotions could use it for evil or ethical purposes. He provides an example of the dark EQ in his article about "one of the most influential leaders who spent years studying the emotional effects of his body language. Practicing his hand gestures and analyzing images of his movements allowed him to become' a spellbinding public speaker,' 'His name was Adolf Hitler". Through this ability to display emotions, he was able to fascinate his followers so much that they stopped thinking and just responded. According to Grant, a person can utilize his social abilities and their high emotional intelligence to dominate the feelings of others, manipulate them, guide them to the wrong path, or use these skills to advance at the expense of others (Adam, 2014).

Similarly, Davis and Nichols (2016), in their article, present a survey of EQ literature to examine whether the trait and ability EQ models contribute to adverse intrapersonal (e.g., Stress reaction) and interpersonal (e.g., emotional manipulation) outcomes. The study found adverse outcomes across multiple contexts (academic, health, and professional life). However, these results were indirect and frequently connected to the personality traits of the person (Davis and Nichols, 2016). Uniquely, Chamorro-Premuzic et al. (2017), in their article "The Downsides of Being very Emotionally Intelligent", they discuss several drawbacks of having high emotional intelligence. According to the authors, various EQ traits are associated with a lower level of creativity and innovation at work. Creativity has long been attached with attributes that describe low emotional intelligence, such as artistic temperament, incompatibility, aggressive impulse. Also, people who allow their feelings and emotions to interfere with their judgments substantially will not be able to deliver or receive negative feedback for concerns of hurting the feelings of others. The researchers also added that the shady side of emotional intelligence could assist individuals with wicked ends into manipulating other people's emotions in a way that serves their agenda (Chamorro-Premuzic and Yearsley, 2017).

These theoretical and empirical studies argue the existence of dark emotional intelligence. EQ is like any set of skill and ability - have two faces - can be used to 
advance oneself and others or can be directed or used for corrupt and selfish intentions. Also, leaders like everybody can eff a dark or personal agenda. Here the leader can utilize his emotional skills to create a subordinate relationship with employees and gain their support to accomplish self-centered goals. This is something that must bear in mind.

\section{CONCLUSION}

Drawing from the present review of emotional intelligence and leadership, we can hypothesize two scenarios of the leader's usage of EQ. The best scenario is that a leader high on emotional intelligence can translate and actualize the reactions and emotions of the employees, and its upshot on their behavior while keeping these emotions under control. Thus, he will be able to maintain the harmony between the employees, energies them, and encourage them. Besides, this will help him to build the necessary trust between the employees. The EQ of the leader plays an essential role in influencing his relationship with the employees, affecting their level of performance, their level of motivation, and their interaction in the work environment. Having a high EQ will help the leader to create an interactive environment, employee commitment, and direct each employee into a more productive and engaging environment.

On the other hand, a leader with high EQ might not be able to direct these skills in the aspired way. For example, his over sensitivity to employees' emotions might make it harder for him to make decisions that touch the employees' feelings. Another example, being too involved with the employee's emotions, could make the leader feel more responsible for the employees' emotions, which might increase his stress level.

The worst scenario, a leader with exalted EQ, utilizes his emotional skills for immoral conduct or morals that pour in his advisable interest. The leader, in this case, can manipulate his employee's emotions to do certain things such as doing unethical practice in his favor. However, the researcher believes that the use of emotional intelligence skills in evil or functional purposes depends on the traits and characteristics of the person himself (dark personality), not on the assumption that he has a high emotional intelligence or not.

The current paper value stems from exploring and providing an understanding of the relationship between EQ and leadership from a conceptual point of view. The paper also presents a thorough examination of the most prominent models of EQ (ability, mixed and traits models), and the differences between these models. Additionally, the study highlighted what is known as the 'dark side' of EQ and its potential adverse effects on leadership.

Based on the current examination, distinct areas of prospective research have been identified. Various researchers have emphasized the importance of EQ in leadership, but these researchers did not address what considered a suitable level of EQ for selecting effective leaders the leader. Furthermore, investigation in the area of the dark side of EQ should be done, such as how the shady side of EQ manifests, or why some leaders with high EQ may decide to use it in adverse ways. Finally, throughout the research, the researcher developed an interest in investigating the relationship between the dark side of EQ and job burnout where the majority of studies investigated the role of EQ in buffering the negative effect of job burnout and stress (e.g.(Mérida-López, Extremera, 2017; Szczygiel Mikolajczak, 2018)) while non-investigated the EQ as a source of burnout. 


\section{REFERENCES}

Adam, G. (2014). The Dark Side of Emotional Intelligence, The Atlantic [Access: 28.03.2018]. Access on the internet: https://www.theatlantic.com/health/archive/2014/01/the-dark-side-ofemotional-intelligence/282720/.

Austin, E.J. et al. (2014). Associations of the managing the emotions of others (MEOS) scale with personality, the Dark Triad and trait EI. "Personality and Individual Differences". Elsevier Ltd, 65. DOI: 10.1016/j.paid.2014.01.060.

Bar-On, R. (2004). The Bar-On Emotional Quotient Inventory (EQ-i): rationale, description and summary of psychometric properties [in:] Geher, G., ed., Measuring emotional intelligence: Common ground and controversy. Nova Science Publishers.

- (2006). The Bar-On model of emotional-social intelligence (ESI). "Psicothema", No. 18(Suppl).

Bratton, A.V.K. et al. (2011). The impact of emotional intelligence on accuracy of self awareness and leadership performance. "Leadership \& Organization Development", No. 23(2). DOI: 10.1108/01437731111112971.Made.

Caruso, D.R., Mayer, J.D., Salovey, P. (2001). Emotional Intelligence and Emotional Leadership [in:] Riggio, R.E., Murphy, S.E., Pirozzolo, F.J., eds, Multiple Intelligences and Leadership. New Jersey: Taylor \& Francis.

Castro, F., Gomes, J., de Sousa, F.C. (2012). Do Intelligent Leaders Make a Difference? The Effect of a Leader's Emotional Intelligence on Followers' Creativity. Creativity and Innovation Management, No. 21(2). DOI: 10.1111/j.1467-8691.2012.00636.x.

Chamorro-Premuzic, T., Yearsley, A. (2017). The Downsides of Being Very Emotionally Intelligent. "Harvard Business Review Digital Articles".

Cherniss, C. (2001). Emotional Intelligence and Organizational Effectiveness [in:] Goleman, D., Cherniss, C., eds, The Emotionally Intelligent Workplace. San Francisco: Jossey-Bass.

Côté, S. et al. (2011). The Jekyll and Hyde of Emotional Intelligence: Emotion-Regulation Knowledge Facilitates Both Prosocial and Interpersonally Deviant Behavior. "Psychological Science", No. 22(8). DOI: 10.1177/0956797611416251.

Davis, S.K., Nichols, R. (2016). Does Emotional Intelligence have a "Dark" Side? A Review of the Literature. "Frontiers in Psychology", No. 7(8). DOI: 10.3389/fpsyg.2016.01316.

Emmerling, R.J., Goleman, D. (2003). Emotional Intelligence: Issues and Common Misunderstanding. "Issues and Recent Developments in Emotional Intelligence, No. 1(1). Access on the internet: http://www.eiconsortium.org.

Gardner, L., Stough, C. (2002). Examining the relationship between leadership and emotional intelligence in senior level managers. "Leadership \& Organisation Development Journal, No. 23(2). DOI: $10.1108 / 0143773021041919$.

Gayathri, N., Meenakshi, K. (2013). A Literature Review of Emotional Intelligence. "International Journal of Humanities and Social Science Invention", No. 2(3).

George, J.M. (2000). Emotions and leadership: The role of emotional intelligence. "Human Relations", No. 53(8). DOI: 10.1177/0018726700538001.

Goleman, D. (1995). Emotional intelligence: Why it can matter more than IQ. New York: Bantam Books.

(1998). Working with emotional intelligence. New York: Bantam Books.

(2002). An EI-Based Theory of Performance [in:] Goleman, D., Cherniss, C., eds, The Emotionally Intelligent Workplace. San Francisco: John Wiley \& Sons. 
Goleman, D., Boyatzis, R., McKee, A. (2002). Primal leadership: realizing the power of emotional intelligence. Boston, Mass: Harvard Business School Press.

Higgs, M., Aitken, P. (2003). An exploration of the relationship between emotional intelligence and leadership potential. "Journal of Managerial Psychology", No. 18(7-8). DOI: 10.1108/02683940310511890.

Kaliská, L., Kaliský, J. (2016). The Potential of Emotional Intelligence in Personality Space. "The New Educational Review", No. 46(4). DOI: 10.15804/tner.2016.46.4.22.

Kerr, R. et al. (2006). Emotional intelligence and leadership effectiveness. "Leadership and Organization Development Journal", No. 27(4). DOI: 10.1108/01437730610666028.

Kilduff, M., Chiaburu, D.S., Menges, J.I. (2010). Strategic use of emotional intelligence in organizational settings: Exploring the dark side. Organizational Behavior. Elsevier Ltd, 30(C). DOI: 10.1016/j.riob.2010.10.002.

Mayer, J.D. et al. (2001). Emotional Intelligence as a Standard Intelligence, "Emotion". DOI: 10.1037//1528-3542.1.3.232.

Mayer, J.D., Caruso, D.R., Salovey, P. (1999). Emotional intelligence meets traditional standards for an intelligence. "Intelligence", No. 27(4). DOI: 10.1016/s0160-2896(99)00016-1. - (2000). Models of emotional intelligence [in:] Sternburg, R.J., ed., Handbook of intelligence. Cambridge: Cambridge University Press.

- (2016). The Ability Model of Emotional Intelligence: Principles and Updates. "Emotion Review", No. 8(4). DOI: 10.1177/1754073916639667.

Mayer, J.D., Dipaolo, M., Salovey, P. (1990). Perceiving Aaffective Content in Ambiguous Visual Stimuli: A Component of Emotional Intelligence. "Journal of Personality Assessment", No. 54(3/4). DOI: 10.1080/09540250600667892.

Mayer, J.D., Salovey, P. (1997). What Is Emotional Entelligence? [in:] Salovey, P., Sluyter, D.J., eds, Emotional development and emotional intelligence: Educational implications. New York: Basic Books.

Mayer, J.D., Salovey, P., Caruso, D.R. (2004). Emotional Intelligence: Theory, Findings, and Implications. "Psychological Inquiry", No. 15(3). DOI: 10.1207/s15327965pli1503_02.

Mérida-López, S., Extremera, N. (2017). Emotional Intelligence and Teacher Burnout: A Systematic Review. "International Journal of Educational Research". Elsevier, 85(July). DOI: 10.1016/j.ijer.2017.07.006.

Nagler, U.K.J. et al. (2014). Is there a "dark intelligence"? Emotional intelligence is used by dark personalities to emotionally manipulate others. "Personality and Individual Differences". Elsevier Ltd, 65(1). DOI: 10.1016/j.paid.2014.01.025.

Nozaki, Y., Koyasu, M. (2013). The relationship between trait emotional intelligence and interaction with ostracized others' retaliation. "PLOS ONE", No. 8(10). DOI: 10.1371/journal. pone. 0077579 .

Olakitan, O.O. (2014). Emotional Intelligence and Perceived Leadership Behaviour Effectiveness in Organizations. "International Journal of Humanities and Social Science", No. 4(2).

Petrides, K.V, Furnham, A. (2000). On the dimensional structure of emotional intelligence. "Personality and Individual Differences", No. 29(2). DOI: 10.1016/S0191-8869(99)00195-6.

- (2001). Trait Emotional Intelligence: Psychometric Investigation with Reference to Established Trait Taxonomies. "European Journal of Personality", No. 15(6). DOI: 10.1002/ per.416. 
- (2003). Trait Emotional Intelligence: Behavioural Validation in Two Studies of Emotion Recognition and Reactivity to Mood Induction. "European Journal of Personality", No. 17(1). DOI: $10.1002 /$ per.466 Trait.

Petrides, K.V., Mavroveli, S. (2018). Theory and Applications of Trait Emotional Intelligence. "Psychology", No. 23(1).

Petrides, K.V (2010). Trait Emotional Intelligence Theory. "Industrial and Organizational Psychology", No. 3(2). DOI: 10.1111/j.1754-9434.2010.01213.x.

Rego, A. et al. (2007). Leader Self-reported Emotional Intelligence and Perceived Employee Creativity: An Exploratory Study. "Creativity and Innovation Management", No. 16(3). DOI: 10.1111/j.1467-8691.2007.00435.x.

Rosete, D., Ciarrochi, J. (2005). Emotional intelligence and its relationship to workplace performance outcomes of leadership effectiveness. "Leadership and Organization Development Journal", No. 26(5). DOI: 10.1108/01437730510607871.

Salovey, P., Mayer, J.D. (1990). Emotional Intelligence. "Imagination, Cognition and Personality", No. 9(3). DOI: 10.2190/dugg-p24e-52wk-6cdg.

Singh, D. (2006). Emotional Intelligence at Work : A Professional Guide. 3th ed. New Delhi: New Delhi Sage Publications. DOI: 10.1017/CBO9781107415324.004.

Szczygiel, D.D., Mikolajczak, M. (2018). Emotional Intelligence Buffers the Effects of Negative Emotions on Job Burnout in Nursing. "Frontiers in Psychology", No. 9 (December). DOI: $10.3389 /$ fpsyg.2018.02649.

Wong, C., Law, K.S. (2002). The effects of leader and follower emotional intelligence on performance and attitude: An exploratory study. "The leadership quarterly", No. 13(3). DOI: 10.1016/S1048-9843(02)00099-1.

DOI: $10.7862 /$ rz.2020.mmr.5

The text was submitted to the editorial office: February 2020.

The text was accepted for publication: March 2020. 